\title{
A Constituição da Escola Normal no Ginásio de Jequié-Ba (1954-1966): Um pouco de sua História
}

Resumo: O presente artigo reporta-se à implantação do Ginásio de Jequié e à constituição da Escola Normal nessa Instituição. Focalizamos o Curso Pedagógico desenvolvido nesse Ginásio, no período de 1954 a 1966, mediante análise de documentos localizados em seu arquivo, jornais e legislação educacional do período, bem como de entrevistas realizadas junto a ex-alunas, ex-professores e ex-secretário do Curso. Centramos nossa atenção para uma história do Ginásio e aspectos sociais e econômicos que influenciaram na sua criação. Destacamos que o Ginásio de Jequié era uma entidade privada e foi o primeiro a ofertar o ensino secundário assim como a implementar a Escola Normal no município de Jequié. A criação do Ginásio de Jequié, em 1935, segue um movimento de oferta do ensino secundário pela iniciativa privada na Bahia. Ao todo, foram 340 normalistas concluintes nesse estabelecimento de ensino, cujo proprietário era o Padre Leônides Spínola de Andrade que também foi seu diretor em todo o período do Curso Pedagógico.

Palavras-chave: História da Educação. História da Educação Brasileira. Instituições Educativas Brasileiras. História da Instituição.

\section{Considerações preliminares}

O Ginásio de Jequié foi o pioneiro a implantar o Curso Pedagógico no município de Jequié-BA. Para a escrita desta história nos valemos da análise de documentos, e das contribuições de depoentes envolvidos nessa instituição de ensino no recorte temporal delimitado - de 1954 a 1966 -, correspondendo ao período de seu funcionamento, ou seja, a partir de registros de sua implantação até a extinção da formação de professores no referido Ginásio. Todavia, retroagimos no tempo para, de forma breve, abordarmos a implantação do Ginásio ocorrida em 1935. Assim, nosso propósito aqui é relatar a implantação do Ginásio de Jequié, bem como a constituição da Escola Normal desse Ginásio. ${ }^{1}$

O Ginásio de Jequié, entidade privada, foi o primeiro a desenvolver o ensino secundário e a Escola Normal no município, e entendemos que a História não é dada, mas construída por meio de fatos históricos, isto é, por acontecimentos que de algum modo interferiram nos rumos de uma sociedade. No caso específico desse Ginásio, ele foi e continua sendo de grande valia para a história da educação e da formação de professores, principalmente da cidade de Jequié, uma vez que durante um período significativo
Marly Gonçalves da Silva Universidade Estadual do Sudoeste da Bahia

mygsilva@gmail.com Janice Cassia Lando Universidade Estadual do Sudoeste da Bahia janicelando@gmail.com

(1) Este artigo traz resultados parciais da pesquisa de mestrado que vinculou-se ao projeto

"Tecendo o processo histórico de profissionalização docente, no âmbito da matemática, nos seus diferentes níveis de formação na Bahia, de 1925 a década de 1980" (LIMA et al., 2016), aprovado por meio do Edital da Chamada Universal MCTI/ CNPQ n. 01/2016. Que por sua vez está atrelado a um projeto de âmbito nacional, coordenado pelo Grupo de Pesquisa História da Educação Matemática no Brasil (GHEMAT Brasil) -, com caráter de investigação "Guarda-Chuva", de modo a abrigar pesquisas de diferentes estados brasileiros, intitulado "A matemática na formação de professores e no ensino: processos e dinâmicas de produção de um saber profissional 1890 - 1990". (VALENTE et al., 2017) 
(2) Disponível em: https:// repositorio.ufsc.br/.

(3) Entrevista concedida à Marly

Gonçalves da Silva, gravada no

dia 4 de novembro de 2017, em

Jequié-BA, para a pesquisa de

Mestrado do PPG-ECFP da UESB.

da existência do Curso Pedagógico não havia outra instituição de ensino que atendesse a esta formação. Dessa forma, essa história deve ser valorizada, pois quando compreendemos nosso passado, avaliamos e refletimos nosso presente, certamente planejamos melhor nosso futuro.

Para sermos mais precisos, recorremos a Eric Hobsbawm (2007, p. 50) que em sua obra Sobre história, faz as seguintes considerações,

[...] passado, presente e futuro constituem um continuum. [...] a maior parte da ação humana consciente, baseada em aprendizado, memória e experiência, constitui um vasto mecanismo para comparar constantemente passado, presente e futuro. As pessoas não podem evitar a tentativa de antever o futuro mediante alguma forma de leitura do passado. Elas precisam fazer isto. Os processos comuns da vida humana consciente, para não falar das políticas públicas, assim o exigem.

O trabalho está apoiado em depoimentos dos sujeitos da pesquisa e documentos do Ginásio, bem como, jornais e a legislação educacional do período. Dos sujeitos envolvidos na pesquisa, aqui abordamos os depoimentos de quatro ex-alunas, dois ex-professores e o ex-secretário do Ginásio que fizeram parte da história do Curso Pedagógico do Ginásio de Jequié.

Os documentos da pesquisa foram localizados, no arquivo do Museu Histórico João Carlos Borges, situado em Jequié; no Arquivo Público do Estado da Bahia (APEB), localizado em Salvador; no arquivo do Ginásio de Jequié; além do Repositório Institucional da Universidade Federal de Santa Catarina ${ }^{2}$ (UFSC).

\section{Trilhando a história do Ginásio de Jequié}

A implantação do Ginásio foi alvo de disputa entre Jequié e Vitória da Conquista como expõe o depoente Emerson Pinto de Araújo $^{3}$ (2017a, grifos nossos),

Eu devo dizer que durante muito tempo Jequié era mais importante do que Vitória da Conquista, porque todo o transporte era feito pela estrada de ferro de Nazaré. [...] Pois bem, Jequié foi crescendo [...] e nesse periodo chegou aqui em Jequié o professor Brito, Antônio Félix de Brito, que foi o primeiro diretor do Ginásio de Jequié. [...] quando teve uma reunião para tratar do assunto, então Conquista querendo puxar e a turma perdeu: Prefiro ficar em Jequié. [...] 
ele então veio pra aqui. Bom ali está, não tem ainda Ginásio, é uma oportunidade para eu me estender lá. [...] Ele disse: Então vamos fundar um em Jequié.

Ficou bem explícita a estreita relação desde outrora mantida entre o sistema educacional e o contexto sócio-político. Mas se pensarmos de outro ângulo veremos que aspectos econômicos foram cruciais e influenciaram toda uma disputa nesse sentido. Araújo (2017b) enfatiza o fato de Jequié não ter sido disseminadora do avanço econômico da região, mas sim favorecida uma vez que se prestou por muito tempo como espaço aos negócios de importação e exportação de produtos, beneficiando-se até meados do século XX de fatores extrínsecos que regrediram tanto quanto o privilégio da cidade em relação aos centros urbanos que antes the tributavam.

Observamos, entretanto, que devido a seus caminhos e meios de transporte, Jequié se desenvolveu economicamente na primeira metade do século XX, principalmente com a proximidade do Rio de Contas, e a construção da Estrada de Ferro de Nazaré que durante seu funcionamento serviu de canal de exportação e importação comercial, favorecendo a expansão populacional. Foi com essa característica de centro urbano importante para a localidade e região que o Ginásio de Jequié foi instituído.

Há de se destacar a contribuição de imigrantes italianos no desenvolvimento comercial de Jequié; Vicente Grillo, por exemplo, ajudou a consolidar planos educacionais, principalmente intervindo na cessão do prédio onde inicialmente funcionou o Ginásio de Jequié.

Importa ressaltar, também, o contexto do oferecimento da educação secundária na Bahia quando da criação do Ginásio de Jequié. De acordo com Santana (2009), no ano de 1939 o Estado contava com uma instituição de ensino secundário pública, 1ocalizada na Capital, o Ginásio da Bahia. Segundo essa autora (2009, p. 343), até o final da década de 1930, "A oferta crescia através do ensino ministrado nos estabelecimentos particulares que eram 19, na capital e 15 no interior". Nesse sentido, Rodrigues (2012, p. 61) afirma que até meados da década de 1940, o ensino secundário prioritariamente estava sob administração particular, o que viria a ser alterado posteriormente.

Somente na década seguinte [1950], é que são efetivamente concretizadas as primeiras iniciativas e tentativas de implantação 
(4) Segundo Rabelo (2005, p. 123), Antônio Félix da Cunha Brito foi um "[...] mestre de elevado nível, vinculado em Salvador ao Colégio Hugo Baltazar [...]".

(5) Rios (2011, p. 26) ao escrever sobre Vicente Grillo indica que ele foi um "Homem de muitas posses, [...] dono de várias propriedades e terras na cidade, [...] Um dos representantes de maior destaque da colônia italiana". O autor aponta ainda que ele nasceu em Gênova, em 1889, chegou em Jequié em 1904 aos 15 anos e faleceu em 08 de junho de 1958. Tendo sido comerciante e agropecuarista; por décadas foi o maior negociante da cidade, e em 1990 foi homenageado tendo seu nome aplicado ao moderno complexo Centro de abastecimento construído. Além de que contratou profissionais para recuperar os estragos provocados na cidade após a enchente de 1914. (RIOS 2011 p. 26) O autor mencionado, bem como Araújo (1997) e Rabelo (2005), descrevem essas e outras contribuições do italiano à cidade de Jequié de forma mais pormenorizada. de políticas de expansão dessa modalidade de ensino, por meio da criação de várias instituições em cidades do interior e na capital, notadamente pela proposta de implantação de um sistema escolar, apresentada pelo educador e então Secretário da Educação e Saúde, Anísio Teixeira, proposta essa que teria como objetivo essencial, segundo o próprio educador, retirar a Bahia do atraso educacional e social em que se encontrava.

Assim, a criação do Ginásio de Jequié, em 1935, segue um movimento de oferta do ensino secundário pela iniciativa privada na Bahia.

\section{Desenvolvendo um pouco da história do Ginásio de Jequié}

Escritores da história da cidade, a exemplo de Araújo (1997), Rios (2011) e Rabelo (2005), são consensuais de que o Ginásio de Jequié foi o primeiro centro de ensino secundário do município, bem como da região, fundado em 1935 com essa denominação pelo educador Antônio Félix da Cunha Brito, ${ }^{4}$ que contou com o apoio do italiano Vicente Grillo, ${ }^{5}$ um dos maiores benfeitores do município, na cessão do espaço - sobrado dos Grillo -, considerado, na época, conforme Rios (2011), o prédio mais importante da cidade, construído com materiais vindos inclusive da Itália.

Ao constatar a problemática referente à adequação de edifícios para o funcionamento de um educandário para o ensino secundário, o Prof. Antônio Félix da Cunha Brito em visita a Jequié na década de 30,

[...] procurou Vicente Grillo e foi categórico: - A vinda de um ginásio para aqui está em suas mãos. Ceda o palacete, e o ginásio será instalado. A resposta veio rápida, sem tergiversação: Bobagem... Se depender somente disso, o ginásio já está fundado. Vou desocupar o prédio e, dentro de oito dias, the entregarei as chaves. (ARAÚJO, 1997, p. 201, grifos do autor).

Ao que consta no desfecho, segundo esse autor, foi preciso mais que isso. Ao anunciar sua decisão em reunião não contou com o apoio de nenhum dos fazendeiros, comerciantes e capitalistas ali presentes ao solicitar um fiador para o aluguel de seu prédio. Apesar disso,

Vendo que o empreendimento poderia ir por água abaixo, em favor de Vitória da Conquista, que acenava com todas as 
vantagens, Vicente Grillo pediu a palavra e, para vexame dos que ali se encontravam, declarou peremptoriamente: Jequié e sua juventude não podem ficar privados de tal melhoria. Com fiador ou sem fiador, o prédio já está cedido e o Prof. Brito só pagará os aluguéis quando quiser e quando puder. (ARAÚJO, 1997, p. 201202, grifo do autor).

Entretanto, essa benfeitoria proveniente de um comerciante estaria sendo inteiramente gratuita em prol do social, ou revestida de interesses políticos e econômicos? Conjecturamos que Vicente Grillo sendo um homem de negócios, provavelmente viu uma grande possibilidade de lucrar com a cessão do prédio. ${ }^{6}$ Diante dessa cessão, podemos também supor que a oferta do ensino secundário no interior baiano neste período, considerando o caso de Jequié, se deu por meio de estabelecimento privado e com incentivo de particulares.

Segundo Rabelo (2005), o tradicional Edifício Grillo foi erguido na Rua 2 de Julho, esquina com a Praça Rui Barbosa, localizada na área central da cidade, o qual serviu para a implantação do Ginásio de Jequié na segunda metade da década de 1930, onde permaneceu até os anos 40.

Quem corroborou com esta historiografia foi Anisia Rosa Tourinho Simões de Carvalho (2017), aluna e professora do Ginásio,

[... o o Ginásio de Jequié foi implantado pelo professor Antônio Brito, aqui na Praça Rui Barbosa, num casarão cedido pelo Sr. Vicente Grillo, italiano, daí o professor Brito construiu o Ginásio [...]. O Padre Spinola veio aqui pra Jequié e comprou o Colégio na mão do professor Brito.

Um novo edifício foi construído, com recursos próprios, na Avenida Rio Branco pelo professor Antônio Felix da Cunha Brito, contendo além da residência para seus familiares um internato para alunos da região sudoestina da Bahia, laboratórios, um auditório transformado mais tarde em cinema (Cine Auditório7), além de uma capela, atualmente incorporada à Diocese local. De acordo com o secretário José Figueirêdo Sampaio (2017), ao adquirir o Ginásio em parceria com o Bispo Dom Florêncio Sisínio Vieira, ${ }^{8}$ o padre Leônides Spínola de Andrade deu continuidade à sua construção, o Bispo, nesta condição, provavelmente pode ter auxiliado de alguma forma na continuidade das obras. Reinaldo Moura Pinheiro (1985a) justificou motivos que levaram a esse feito:
(6) O prédio serviu como primeira agência do Banco do Brasil e outras entidades significativas, era motivo de orgulho dos habitantes do município após a enchente de 1914. (RABELO, 2005) Veio a ruir a parte superior em junho de 1989, sendo demolido mais tarde. (RIOS, 2011) Para Araújo (1997), sua demolição ainda em 1989 foi criminosa. Mas de acordo com o jornalista Zenilton Meira (2016), o prédio desmoronou parte do seu telhado, afetando a lateral que situava à Rua Dois de Julho; tijolos atingiram veículos culminando em um acidente fatal de um garoto, como não houve manifestação nem dos proprietários nem do poder público, foi feita a sua demolição total.

(7) Atualmente funciona o Teatro Municipal, chamado Palácio das Artes.

(8) Dom Florêncio Sisínio Vieira foi o primeiro Bispo da diocese instalada na cidade de Amargosa, com área geográfica desde o litoral até a divisa com o Estado de Minas Gerais; dela originou-se as Dioceses de Vitória da Conquista e a de Jequié. Atuou no período de 1942 a 1969 quando renunciou. A diocese é referenciada pela contribuição de seus "Bispos, Sacerdotes, Religiosos, Religiosas e Leigos, de modo particular na formação do clero, na estruturação de uma pastoral de conjunto, na formação das comunidades eclesiais, na educação, da promoção da dignidade humana e defesa dos seus direitos". (CONFERÊNCIA NACIONAL DOS BISPOS DO BRASIL, 2012) 
Fundado em 1935, pelo emérito Prof. Antônio Félix da Cunha Brito, foi instalado de início no prédio Vicente Grilo [sic]. A pequena escola torna-se grande depressa. E o Prof. Brito não resumiu o seu ideal apenas na fundação da escola, por isso, constrói na Colina do Sol um novo prédio dentro das exigências pedagógicas modernas: salas amplas, arejadas e iluminadas; laboratórios científicos, áreas esportivas e de lazer, sem falar na formação de uma poderosa equipe docente que aguardava o potencial inteligente da juventude estudantil de Jequié.

Logo, conjecturamos que uma possível ampliação de matrícula e de cursos pode ter motivado a mudança de sede do Ginásio, bem como adequação estrutural às demandas pedagógicas modernas.

A modernidade pedagógica, segundo Carvalho (2000), corresponde aos modelos pedagógicos que se configuraram nas cinco primeiras décadas republicanas, em especial no estado de São Paulo, mas que influenciaram outros estados brasileiros. Essa autora destaca como suas principais características: "[...] ensino seriado; classes homogêneas e reunidas em um mesmo prédio, sob uma única direção; métodos pedagógicos modernos utilizados na Escola Modelo anexa à Escola Normal e monumentalidade dos edifícios em que a instrução pública se faz signo do progresso." (CARVALHO, 2000, p. 112), inclui, também, "[...] ensino simultâneo, regulamentação e uniformização do tempo escolar, enquadramento disciplinar, organização do espaço escolar, etc.". (CARVALHO, 2000, p. 115) Como métodos pedagógicos modernos, essa autora (2000) indica dois modelos concorrentes: o método intuitivo e a escola nova.

Nesse sentido, segundo Bencostta (2001, p. 106), houve a necessidade de projetos específicos para organização do espaço escolar que "[...] se adequassem às novas metodologias de ensino propaladas pelo discurso de uma moderna pedagogia". Além dos critérios de higiene, iluminação e ventilação, "os espaços funcionais que a moderna pedagogia exigia, como gabinete para diretor, biblioteca, anfiteatro, laboratórios, secretaria, oficinas, pátios etc." (BENCOSTTA, 2001, p. 136)

O Padre Spínola adotou como lema do Ginásio a seguinte frase em latim: SIC ITUR AD ASTRA, que foi comentado por vários depoentes. Iracema Ramos Campos (2018) interpretou-a como "Assim se vai aos astros", ou "Se estudares alcançarás as estrelas". E José Figueirêdo Sampaio (2017) a explicou como "Assim chegaremos às alturas". Esta frase se encontrava escrita em um livro aberto 
que representava o escudo que simbolizava o Ginásio bem como a Escola Normal.

Outra consideração que convém assinalar é sobre o símbolo de nobreza do padre Spínola - Marquês de Monte Maggiori -, pois independente da forma como o adquiriu, se por descendência familiar ou por compra de título, ele valorizava de tal forma que expôs à frente do Ginásio ${ }^{9}$ vinculando o mesmo à sua pessoa.

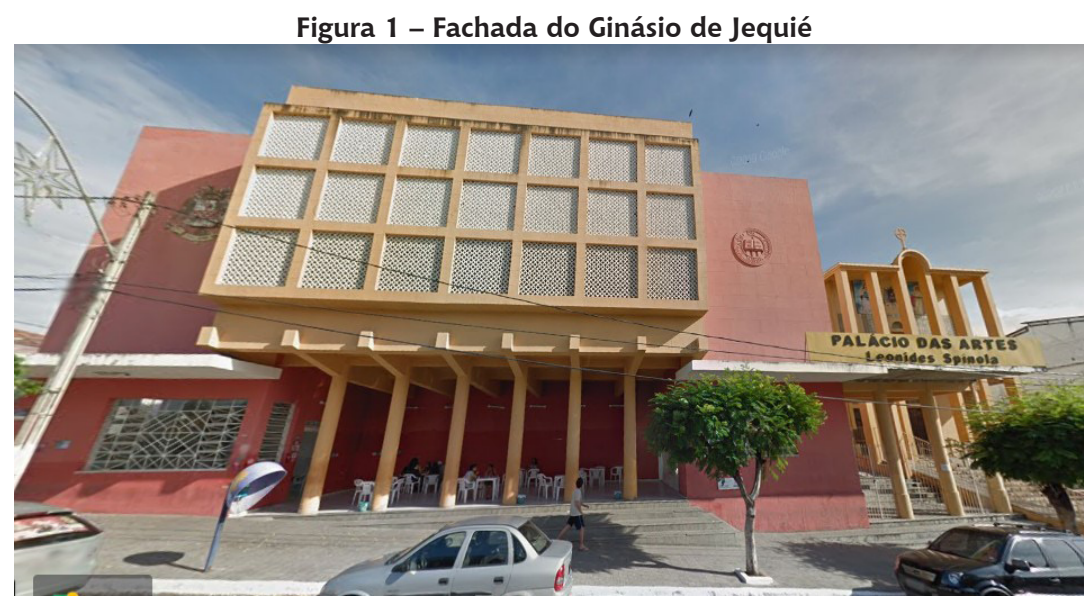

Fonte: Google, 2020.

No que tange à autorização de funcionamento e ao reconhecimento do Ginásio de Jequié, encontramos em anexo ao Relatório da Primeira Prova Parcial de $1956,{ }^{10}$ datado de 2 de agosto do mesmo ano, um documento do ano 1974 assinado pelo então diretor Bel. Amando Ribeiro Borges, a informação que o Ginásio de Jequié foi autorizado a funcionar em 23 de novembro de 1935 e reconhecido pelo Decreto-Lei no 19.990 de 26 de novembro de 1945.

Já a Escola Normal foi anexada ao Ginásio de Jequié em 1954 por meio da implantação do Curso Pedagógico destinado à formação de professores para o Ensino Primário. O decreto que autorizou o seu funcionamento é o de $\mathrm{n}^{\circ} 15.990$ de 09 de outubro de 1954 (COMUNICADO DE AUTORIZAÇÃO..., 1955), para que em 1955 inaugurasse nova turma do Intermediário, e desse continuidade à do ano anterior como o Primeiro Pedagógico, pois inicialmente a formação, desenvolvida em três anos, tinha como denominação Série Intermediária, na $1^{\mathrm{a}}$, e as duas últimas $1^{\mathrm{a}}$ e $2^{\mathrm{a}}$ Série Pedagógico. Devido a uma reformulação no ano de 1962, posteriormente passou a ser três Séries Pedagógico.
(9) Disponível em: https://earth. google.com/web/@-13.85609947,40.08009585,208.60020447a,0d,90 y,141.11611735h,102.53558189t,0r/ data $=$ IhoKFkZWa094ZG9PbkNJcml INHIwTF9BbmcQAg

(10) RELATÓRIO da primeira prova parcial, junho de 1956. Arquivo do Ginásio de Jequié

RELATÓRIO Inicial, ano de 1975. Arquivo do Ginásio de Jequié. 
(11) Não obtivemos dados precisos quanto ao período desta dissolução, entretanto no arquivo do Ginásio de Jequié os últimos registros encontrados (Livro: Burocrático), com indícios de pagamentos destinados ao Bispo, são datados de 1950.

(12) Estudou no Ginásio de Jequié e foi coroinha. E o atual proprietário das instalações onde funcionou o Ginásio e posteriormente o CEMS.

(13) Segundo informações obtidas junto à última secretária do CEMS,

e dados do Instituto Nacional de

Estudos e Pesquisas Educacionais

Anísio Teixeira (INEP). Dermival Rios

(2011) informa sua extinção a partir

\section{Fragmentos de uma história da Escola Normal do Ginásio de Jequié}

Para entender as razões pelas quais as escolas particulares foram autorizadas a ofertar o ensino normal, buscamos amparo na literatura, e a partir de Almeida (2006, p. 73) percebemos que,

Dada a importância que os liberais republicanos atribuíam à escola, o magistério e a educação eram vistos como instrumentos eficazes e determinantes para a formação de profissionais encarregados de exercer o ensino. Porém, as escolas normais públicas eram insuficientes para atender à demanda, e logo se estendeu a autorização de funcionamento para escolas normais livres particulares e municipais.

Segundo o secretário José Figueirêdo Sampaio (2017), o Padre Spínola desfez a sociedade ${ }^{11}$ com Dom Florêncio Sisínio Vieira que morava em Amargosa, passando a ser o único proprietário do Ginásio, e mesmo indo trabalhar em outro município continuou sendo de sua propriedade, apenas gerido por outros administradores. Ele justificou o término da sociedade pelo fato do Bispo não poder dar assistência ao Ginásio visto que ficava muito ocupado com suas obrigações religiosas na diocese de Amargosa.

Conforme Pinheiro (1985b), o padre administrou o Ginásio até ser sucedido em junho de 1966 por Dr. Hernani Veloso Viana quando fora nomeado para o Tribunal de Contas do Estado, e em seguida, Dr. Amando Ribeiro Borges responsabilizou-se pela direção do colégio a partir de 1971.

Durante a administração de Dr. Amando Ribeiro Borges, mais precisamente em 1974, o Ginásio de Jequié passou a denominar-se Centro Educacional Ministro Spínola (CEMS), em homenagem ao seu ex-diretor Padre Leônides Spínola, (julgamos que este foi um dos motivos que o levou a ser popularmente chamado de Colégio do Padre associado ao fato de ter sido proprietário).

E por fim, a partir de 1979 o educador Reinaldo Moura Pinheiro ${ }^{12}$ assumiu sua administração até 2007 quando a partir de então foi desativado. ${ }^{13}$

Em entrevista concedida a Miguel José da Silva a professora Sisínia Vieira Matos, sobrinha do Bispo Dom Florêncio Sisínio Vieira, expôs seu empenho na educação, ou seja, 
[...] um dos objetivos dele era trabalhar para melhorar o nível educacional de toda a diocese, então ele começou aqui por Amargosa. Ele veio para aqui em 1942 e em 1946 as irmãs (Sacramentinas) já estavam aqui com um colégio. E ele construiu aquele colégio com todo sacrifício, mas era aquele ideal dele. Na época em que ele chegou aqui o nível educacional de Amargosa era ainda muito deficiente. (MATOS, 2003 apud SILVA, 2013, p. 21).

Silva (2013) avalia que o Bispo dedicou-se para corresponder aos ideais da igreja católica no país em afirmar sua presença na educação da juventude, bem como instituir um curso ginasial almejado pelos mais abastados da população, já que a instituição seria privada; desta forma, as religiosas do Santíssimo Sacramento aceitaram seu convite, pois pretendiam estender suas atividades educacionais e religiosas, já que até então só existiam escolas primárias.

Assim, o interesse de dois religiosos na aquisição de um ginásio e oferecimento do Curso Pedagógico não se manifestou apenas em Jequié. Além do Colégio em Amargosa, já mencionado, em outras regiões da Bahia também houve influência da religião católica na educação e na formação de professores primários, para ilustrar podemos indicar: o Instituto Nossa Senhora da Piedade, implantado pelas religiosas Ursulinas em Ilhéus, no ano de 1916, com início das atividades da Escola Normal desse Instituto em 1920 (NOGUEIRA, 2016); o Colégio Luzia Silva, criado pela ordem religiosa das Franciscanas Imaculatinas, no ano de 1950, e o Colégio Pio XII fundado em 1961 pelos frades Capuchinhos, ambos em Jaguaquara conforme descrição de Ferreira (2016); bem como a Escola Normal em Serrinha criada na década de 1950 sob influência do Padre Demócrito, conforme apontado em Santos (2006).

Ainda acerca do Colégio de Amargosa, Silva (2013) discorre que a Madre Santa Sofia, em carta enviada ao deputado estadual Waldir Pires em 6 de abril de 1955, solicita ao governo do estado a equiparação do Curso Normal de Amargosa aos demais, citando Jaguaquara e Jequié como exemplos de Cursos Pedagógicos realizados em três anos, uma vez que o de Amargosa fora decretado com a duração de dois anos. Ela questionara a superioridade do Pedagógico em relação ao Normal, pois este não ofertava a disciplina Pedagogia cobrada em concursos, assim a evasão já se dava ao findar a quarta série ginasial; sua resposta foi favorável anunciando 
a decisão da assembleia em decretar lei de igualdade de currículo do Curso para as escolas do interior e da capital.

Com o teor de sua resposta, Silva (2013) pondera que ficou nítida uma diferenciação quanto à localização da instituição para a equiparação da duração dos cursos, mas entendemos que o que definiria de fato o modo de oferta seria o tipo de entidade, pois o professor Paulo de Almeida Campos, Assistente da Divisão de Estudos e Pesquisas Educacionais do Centro Brasileiro de Pesquisas Educacionais (CBPE), emitiu um parecer em resposta à Secretaria de Educação da Bahia que enviou um anteprojeto de lei do ensino normal ao Instituto Nacional de 'Estudos Pedagógicos' (INEP) requisitando sugestões no qual explicitava que,

[...] o 'ensino ministrado nos cursos normais de estabelecimentos públicos e nos cursos pedagógicos de estabelecimentos particulares' se destina ao 'preparo e à formação' dos professores primários e que visa, no primeiro ano, a 'consolidar o preparo científico dos normalistas' e, nos dois anos subseqüentes, "sua formação técnica'. (CAMPOS, 1958, p. 92, grifos do autor)

Nesses parâmetros, o Ginásio de Amargosa enquanto instituição privada poderia ofertar o Curso Pedagógico, tanto é que conseguiu seu propósito, isso nos levou a ponderar que possivelmente questões de ordem política e religiosa - especialmente a Igreja Católica - tenham influenciado. Ao mesmo tempo isso nos despertou a curiosidade para a implantação do curso no Ginásio de Jequié e atentamos para a possibilidade do decreto que mencionamos não ter sido o primeiro a autorizar o funcionamento da Escola Normal e sim uma alteração, até porque ele foi publicado em outubro de 1954 quando o Curso Pedagógico já estava em desenvolvimento.

Há diários de classe e atas de provas com uma ou outra nomenclatura, uns como Curso Normal, outros como Curso Pedagógico. Estes documentos indicam que o curso começou no início do ano de 1954. Ao procurar entender o texto de seu decreto de autorização de funcionamento encontramos o que enuncia o artigo 24 do Decreto $n^{0} 11.762$ de 21 de novembro de 1940: "Os estabelecimentos que mantenham curso secundário sob inspeção federal poderão requerer fiscalização estadual para o curso pedagógico". (BAHIA, 1940) Isso denota que o Ginásio passou por uma fiscalização requisitando o referido curso e foi contemplado, pelo menos, é o que supomos. 
Vale salientar que, segundo os depoentes, foi o Padre Spínola quem acompanhou toda a duração do Curso Pedagógico do Ginásio até a última turma que findou em $1966 .{ }^{14}$ Mesmo não atuando mais como diretor continuou assistindo o Ginásio, e mais, zelando pelas alunas normalistas e seu percurso formativo, pois viajava constantemente entre Salvador e Jequié, inclusive para garantir que ocorresse a contento a formatura da última turma. Ao todo foram diplomadas trezentas e quarenta normalistas, de acordo com o livro de registro de diplomas localizado no arquivo do Ginásio de Jequié.

Percebemos a importância do papel desempenhado pelo diretor escolar e associamos ao ofício do Padre Spínola enquanto mentor pedagógico, pois ele não só administrou o Ginásio e a Escola Normal como também lecionou, inclusive disciplinas pedagógicas.

A Enciclopédia dos Municípios Brasileiros (FERREIRA, 1958) registra o Ginásio de Jequié como um dos estabelecimentos de ensino secundário no município em 1956, cuja matrícula inicial era de trezentos e quarenta e nove alunos. A obra expõe ainda os dados iniciais de matrícula da Escola Normal de Jequié (112 alunos), Escola Técnica e de Comércio de Jequié (79) bem como o Curso básico (157) do mesmo Ginásio.

Quando fundado em 1935 por Antônio Félix da Cunha Brito, instalou-se no Ginásio o Curso Secundário (PINHEIRO, 1985a). Segundo Rabelo (2005) lá havia o Curso Especial, direcionado aos alunos que iam prestar exame de admissão ao Ginásio, bem como o curso secundário ofertado em cinco anos com um currículo que requeria muito estudo do aluno que ao final era certificado como bacharel em Ciências e Letras com toda solenidade de uma formatura.

O Ginásio de Jequié também foi a base da Escola de Contabilidade. Segundo Emerson Pinto de Araújo (2017a) e José Figueirêdo Sampaio (2017) o padre Leônides Spínola de Andrade fundou esse curso, também conhecido como de comércio. É mister frisar que foram encontrados no arquivo ${ }^{15}$ do Ginásio registros referente aos cursos de $2^{\circ}$ grau: Série Básica, Magistério, e Eletromecânica no ano de 1975, além de ter funcionado como centro de instrução pré-militar. ${ }^{16}$

Já o Instituto de Educação Regis Pacheco (IERP) ${ }^{17}$, atual CEEP, ${ }^{18}$ inaugurado em 1952, sob a denominação Ginásio Estadual de Jequié, posteriormente implantou o Curso Normal e também foram criados os cursos clássico e científico, bem como o de comércio passando o estabelecimento a receber o nome de Colégio
(14) Pinheiro (1985b) confirma a substituição do Padre Spínola como diretor do Ginásio em junho de 1966 pelo professor Dr. Hernani Veloso Viana, fato que é citado por Dinalva Souza da Fonsêca (2018) e reforçado por Vilma Vieira Pereira (2018), ambas alunas da última turma do Curso Normal, que concederam entrevista a Marly Gonçalves da Silva gravadas em 16 de março e dia 9 de março de 2018, respectivamente, em Jequié-BA

15) Relatório Inicial do ano 1975. 16) Vários documentos do Ginásio Ihe referencia com um n ${ }^{\circ} \mathrm{CIP}$, pois a Legislação (RIO DE JANEIRO, 1942) determinou que "Art. $3^{\circ}$ Todos os estabelecimentos de ensino, públicos ou particulares, existentes no país, com mais de cinquenta alunos nas condições do art. $1^{\circ}$ deste decreto-lei, são obrigados a manter um centro e instrução premilitar. Art. $4^{\circ}$ Perderão a equiparação ou o reconhecimento federal os estabelecimentos de ensino estaduais, municipais ou particulares sujeitos à obrigação determinada pelo artigo anterior, se não a cumprirem. Art. $5^{\circ} \mathrm{Os}$ centros de instrução premilitar serão designados pelo prefixo C.I.P., seguido do número da respectiva Região Militar e de outro que indique a ordem cronológica de seu registo [Sic]"

17) Para saber mais sobre a história deste Instituto ver Santos (2018).

18) Centro Estadual de Educação Profissional em Gestão e

Tecnologia da Informação Regis Pacheco. 
Estadual de Jequié; assim, muitos não precisaram se deslocar para fora da cidade e se dirigiam para lá e faziam o curso científico como ocorreu com Reinaldo Moura Pinheiro (2005), mediante seu relato em Rabelo (2005).

Os alunos do Ginásio de Jequié correspondiam, em sua maioria, à elite local e da redondeza, ou seja, pessoas com maior poder aquisitivo. Como havia um internato masculino, atendia também a muitos alunos das cidades circunvizinhas. Com relação à Escola Normal, predominaram mulheres, parte delas com condições financeiras, mas que não tiveram permissão familiar para continuar os estudos em outra localidade, e outras de classes menos favorecidas beneficiadas com bolsa de estudo. No que tange ao corpo docente, obtivemos informações de que médicos, advogados, promotores, juízes, biólogos, contadores, normalistas, padres, engenheiros e professores não licenciados lecionaram no Ginásio e muitos também contribuíram para a formação de professores do Curso Pedagógico.

Vale ressaltar que o Ginásio de Jequié era de Entidade mantenedora particular conforme atestam os depoentes e o relatório de 1956 anteriormente citado. Seu último gestor, Reinaldo Moura Pinheiro, quando o Ginásio já possuía a nomenclatura CEMS, afirmou - em sua carta de homenagem ao cinquentenário do Ginásio -, que este começou de forma promissora, "[...] amparado pela sociedade jequieense e por um grupo de intelectuais, idealistas da terra". (PINHEIRO, 1985b)

Com essa afirmação de Pinheiro (1985b) acerca do apoio da sociedade ao Ginásio, podemos interpretar que mesmo não havendo o auxílio financeiro solicitado na época de sua implantação, conforme já mencionado por meio de Araújo (1997), houve contribuição na medida em que matricularam seus filhos e muitos se manifestaram contrários quando se suscitou a ideia da criação do Ginásio público Estadual, pois consideravam que isso prejudicaria o Ginásio privado de Jequié, como apontado em Santos (2018). Essa autora (2018) indica que as manifestações contrárias se deram por parte de membros da elite conservadora local, vereadores e questões político-partidárias que defendiam a manutenção do Ginásio do Padre Spínola.

Interpretamos que o professor Reinaldo se referiu também aos pais que acreditavam e apostavam nos ideais do Ginásio e matriculavam seus filhos para melhor guiar seus destinos; as alunas depoentes foram unânimes ao declararem sua gratidão ao 
Ginásio nesse sentido, gratidão essa extensiva aos seus pais, ao Padre Spínola e aos seus professores, como este testemunho de Dinalva Souza da Fonsêca (2018),

[...] valeu a pena porque se eu fui uma boa professora eu devo muito ao Ginásio do padre. [...] Mas eu tive uma boa formação. Se hoje eu sou o que eu sou devo primeiro aos meus pais que souberam me educar e me colocaram em um colégio bom daqueles [...].

Para não citar todas as alunas depoentes, eis mais uma representação deste reconhecimento, feito por Iracema Figueiredo Ramos Campos (2018),

Hoje eu digo a você como profissional, sou funcionária pública federal, fui professora também no Estado, e digo a você que eu tenho muito a agradecer ao Ginásio de Jequié. Era um ensino de alta qualidade, os professores eram de alto nível e o Padre Spinola considero um benemérito na educação.

Aquele Colégio ali para mim, sinceramente o que eu sou, sem usar falsa modéstia, por onde passei meu trabalho graças a Deus sou bem conceituada, não vou usar falsa modéstia e devo tudo ao Ginásio de Jequié.

Mediante esclarecimento da professora Dayse Maria Meira Britto (2017) o curso primário foi implantado no Ginásio, mas como inicialmente havia cinco turmas, as normalistas eram sorteadas para estagiar lá, seguindo as demais para outras instituições. Encontramos em meio aos documentos no arquivo do Ginásio a menção à Escola Primária Dom Bosco anexa ao Ginásio o que indica a sua nomenclatura, e no Jornal Jequié (PINHEIRO, 1985a) Reinaldo Pinheiro faz alusão de que o Padre Spínola se inspirava na Pedagogia de Dom Bosco.

É importante frisar que a existência dessa escola primária era útil no exercício da prática pedagógica dos futuros professores e cumpria a exigência da legislação. Ou seja, em atendimento ao artigo 42 da Lei Orgânica do Ensino Normal (BRASIL, 1946), a "f) existência de escola primária anexa, para a demonstração e prática de ensino", era uma das exigências da lei para que os estabelecimentos, seja municipais ou particulares, obtivessem a outorga de mandato de ensino normal. 
Quanto à inspiração pedagógica, o sistema preventivo de educação salesiana, de acordo com Cabrino (2009), é que demarca os ideais do padre italiano João Bosco, e remete ao século XIX. Esse sistema ancora-se na tríade razão, religião e amabilidade. Dom Bosco pregava e cultuava práticas educativas que caracterizaram a cultura escolar dos colégios salesianos. O princípio singular deste sistema traduz-se no lema: "formar bons cristãos e honestos cidadãos" (CABRINO, 2009, p. 38), pela incorporação de valores morais e de conduta na educação-formação de jovens e adolescentes.

\section{Considerações finais}

O Ginásio de Jequié deve ser lembrado como o pioneiro na formação de professores no município que ao anexar a Escola Normal possibilitou a habilitação de professores para o Ensino Primário na localidade e região. Foram ao todo 340 normalistas concluintes numa instituição privada e administrada por um padre em todo o período do Curso Pedagógico, que sob esta denominação perdurou por treze anos indo de 1954 a 1966, mas desenvolvendo inicialmente o primeiro ano como Série Intermediária.

O Padre Spínola não só administrou o Ginásio e a Escola Normal como também atuou enquanto mentor pedagógico, dada a relevância atribuída ao seu papel.

Vale destacar que o Ginásio também introduziu o Ensino Secundário em Jequié, apesar de que nem toda a comunidade pôde ter acesso por questões sociais e principalmente econômicas. A existência de uma escola primária também anexa ao Ginásio de Jequié era útil no exercício da prática pedagógica dos futuros professores e cumpria a legislação que exigia a sua existência.

Apesar do Ginásio já estar desativado foi possível ter acesso a seu arquivo no qual localizamos documentos como diários de classe, históricos de alunas, livros de atas, e relatórios de provas parciais e finais com listas de pontos para exames, e também de provas orais.

A história oral foi uma das formas de produção de fontes históricas da pesquisa por entendermos que os depoentes que vivenciaram esta história sobre a qual tecemos uma narrativa eram imprescindíveis para a compreensão e sistematização desta.

O Ginásio de Jequié possibilitou a continuidade dos estudos àqueles que só cursaram o primário, quando anexou a Escola Normal deu margem para a formação de professoras no Curso Pedagógico 
que até então, em ambas as situações, deviam se deslocar para outra cidade. Permitiu também que professoras que já lecionavam obtivessem uma formação para o exercício da docência. A existência do internato masculino facultou o estudo de alunos das cidades próximas. Segundo Rabelo (2005) lá havia o Curso Especial, direcionado aos alunos que iam prestar exame de admissão ao Ginásio. Funcionou no Ginásio também a Escola Técnica e de Comércio de Jequié conhecida como Escola de Contabilidade; o Magistério, e Eletromecânica. O curso secundário certificava bacharéis em Ciências e Letras com direito a solenidade de uma formatura. Essas são algumas contribuições que podemos registrar sobre o legado do Ginásio de Jequié.

\title{
The Constitution of the Normal School in the Jequié Gymnasium of Jequié-Ba (1954-1966): A little of its \\ History
}

\begin{abstract}
The present article refers to the implementation of the Gymnasium of Jequié and the constitution of the Normal School in this institution. We focused on the Pedagogical Course developed in this Gymnasium, from 1954 to 1966, by means of analysis of documents located in its archive, newspapers and educational legislation of the period, as well as interviews with former students, former teachers and former secretary of the Course. We focused our attention on a history of the Gymnasium and social and economic aspects that influenced its creation. We emphasise that the Gymnasium of Jequie was a private entity and was the first to offer secondary education as well as to implement the Normal School in the municipality of Jequié. The creation of the Gymnasium of Jequié in 1935 follows a movement of offering secondary education through private initiative in Bahia. Altogether, there were 340 concluding normalists in this educational establishment, whose owner was Father Leônides Spínola de Andrade, who was also its director throughout the Pedagogical Course.
\end{abstract}

Keywords: History of Education. History of Brazilian Education. Brazilian Educational Institutions. History of the Institution.

\section{La Constitución de la Escuela Normal en el Liceo de Jequié (1954-1966): Un poco sobre su Historia.}

Resumen: Este artículo discurre se refiere a la implantación del Liceo de Jequié y a la constitución de la Escuela Normal en esa institución. Nos concentramos en el Curso Pedagógico desarrollado en ese Liceo, en el período de 1954 a 1966, mediante un análisis de documentos localizados en su archivo, en revistas y en la legislación educacional de ese período, bien como de entrevistas realizadas junto a exalumnas, exprofesores y exsecretario del Curso. Prestamos especialmente atención a una historia del Liceo y a los aspectos sociales y económicos que influenciaron en su creación. Destacamos que 
el Liceo de Jequié era una entidad privada y que fue el primero a ofertar la enseñanza secundaria, así como a implementar la Escuela Normal en el municipio de Jequié. La creación del Liceo de Jequié en 1935 sigue un movimiento de oferta de la enseñanza secundaria por la iniciativa privada en Bahia. En total, fueron 340 normalistas concluyentes en ese establecimiento de enseñanza, cuyo propietario era el Padre Leônides Spínola de Andrade, que también fue su director en todo el período del Curso Pedagógico.

Palabras Clave: Historia de la Educación. Historia de la Educación Brasileña. Instituciones Educativas Brasileñas. Historia de la Institución.

\section{Referências}

ALMEIDA, J. S. de. Mulheres na Educação: missão, vocação e destino? A feminização do magistério ao longo do século XX: professores, alunos e métodos de ensino. In: SAVIANI, D. et al. O legado educacional do século XX no Brasil. 2. ed. Campinas: Autores Associados, 2006. p. 59-107.

ARAÚJO, É. P. de. Capítulos da história de Jequié. Salvador: EGB editora, 1997.

ARAÚJO, É. P. de. Entrevista [04 nov. 2017a]. Entrevistadora: Marly Gonçalves da Silva (arquivo particular). Entrevista gravada no dia 04 de novembro de 2017, em Jequié-BA, para a pesquisa de Mestrado do PPGECFP da UESB.

ARAÚJO, É. P. de. A nova história de Jequié. Salvador: Assembleia Legislativa, 2017b. 514p.

BAHIA. Decreto-lei n. 11.762, de 21 de novembro de 1940. Dispõe sobre a estrutura administrativa do ensino no Estado da Bahia. Palácio do Governo do Estado da Bahia, Salvador, 21 nov. 1941. Disponível em: https://repositorio.ufsc.br/bitstream/handle/123456789/157214/ Decr.\%2011.762_1940.\%20pt\%206.pdf? sequence = 6\&isAllowed = y. Acesso em: 14 ago. 2018.

BENCOSTTA, M. L. A. Arquitetura e espaço escolar: reflexões acerca do processo de implantação dos primeiros grupos escolares de Curitiba (1903-1928). Educar, Curitiba, n. 18, p. 103-141, 2001.

BRASIL. Decreto-lei n. 8.530, de 2 de janeiro de 1946. Lei orgânica do ensino normal. Diário Oficial da União, Rio de Janeiro, 4 jan. 1946. Seção 1, p. 116. Disponível em: http://www2.camara.leg.br/ legin/fed/declei/1940-1949/decreto-lei-8530-2-janeiro-1946-458443publicacaooriginal-1-pe.html. Acesso em: 15 jun. 2017.

BRITTO, D. M. M. Entrevista [22 nov. 2017]. Entrevistadora: Marly Gonçalves da Silva (arquivo particular). Entrevista gravada no dia 22 de novembro de 2017, em Jequié-BA, para a pesquisa de Mestrado do PPGECFP da UESB. 
CABRINO, J. P. Sistema preventivo de educação: vivência e prática da cultura escolar nas olimpíadas salesianas. 2009. Dissertação (Mestrado em Educação) - Universidade de Sorocaba, Sorocaba, 2009.

CAMPOS, P. A. [Parecer referente ao] Projeto de reorganização do ensino normal da Bahia. Revista Brasileira de Estudos Pedagógicos, Rio de Janeiro, v. 29, n. 70, p. 89-101, abr./jun. 1958.

CAMPOS, I. R. F. Entrevista [28 mar. 2018]. Entrevistadora: Marly Gonçalves da Silva (arquivo particular). Entrevista gravada no dia 28 de março de 2018, em Jequié-BA, para a pesquisa de Mestrado do PPGECFP da UESB.

CARVALHO, A. R. T. S. Entrevista [27 nov. 2017]. Entrevistadora: Marly Gonçalves da Silva (arquivo particular). Entrevista gravada no dia 27 de novembro de 2017, em Jequié-BA, para a pesquisa de Mestrado do PPGECFP da UESB.

CARVALHO, M. M. C. Modernidade pedagógica e modelos de formação docente. São Paulo em Perspectiva, São Paulo, v. 14, n.1, p. 111-120, 2000.

CONFERÊNCIA NACIONAL DOS BISPOS DO BRASIL - CNBB. A

Diocese de Amargosa celebra 70 anos de sua criação e instalação. 2012.

Disponível em: http://www.cnbb.org.br/a-diocese-de-amargosa-celebra70-anos-de-sua-criacao-e-instalacao/. Acesso em: 10 ago. 2018. Não paginado.

FERREIRA, J. P. (org.). Enciclopédia dos municípios brasileiros. Rio de Janeiro: IBGE, 1958. (v. XX - Bahia A-L).

FERREIRA, M. M. B. de A. Uma história do ensino de matemática no Colégio Luzia Silva. 2016. 130 f. Dissertação (Mestrado em Educação Científica e Formação de Professores)- Departamento de Ciências Biológicas, Universidade Estadual do Sudoeste da Bahia, Jequié, 2016.

FONSÊCA, D. S. da. Entrevista [16 mar. 2018]. Entrevistadora: Marly Gonçalves da Silva (arquivo particular). Entrevista gravada no dia 16 de março de 2018, em Jequié-BA, para a pesquisa de Mestrado do PPGECFP da UESB.

GOOGLE. Google Earth website. 2020. Ginásio de Jequié [atual CEMS], Jequié, BA. Coordenadas 1351'21"S e 4004'48"W. Edifício em 3D, elevação 209m. Acesso em: 17 set. 2020. Disponível em: http://earth. google.com/web/.

HOBSBAWM, E. Sobre história: ensaios. 2. ed. São Paulo: Cia das Letras, 2007.

LIMA, E. B. et al. Tecendo o processo histórico de profissionalização docente, no âmbito da matemática, nos seus diferentes níveis de formação na Bahia, de 1925 a década de 1980. Projeto de Pesquisa Chamada MCTI/CNPQ No 01/2016 - Universal - faixa A, 2016.

LIVRO: Burocrático, anos de 1945 a 1953. Arquivo do Ginásio de Jequié. 
MEIRA, Z. História de Jequié: 27 anos da queda do prédio Grillo em Jequié. Disponível em: https://www.skyscrapercity.com/threads/ jequi\%C3\%A9-ba.1514765/page-162\#post-134212808. Acesso em: 16 jan. 2019.

NOGUEIRA, R. A. A grande conquista do projeto educacional. In: NOGUEIRA, R. A. (coord.); comissão de coordenação SILVEIRA, Alfredo Amorim et al. Histórias e memórias do centenário do Instituto Nossa Senhora da Piedade: 100 anos de existência 1916-2016. Ilhéus: Editus, 2016. p. 90-119.

PEREIRA, V. V. Entrevista [09 mar. 2018]. Entrevistadora: Marly Gonçalves da Silva (arquivo particular). Entrevista gravada no dia 09 de março de 2018, em Jequié-BA, para a pesquisa de Mestrado do PPGECFP da UESB.

PINHEIRO, R. M. 1985: Cinquentenário do CEMS. Jornal de Jequié. Jequié, [1985a]. Não paginado.

PINHEIRO, R. M. Um pouco da história. (Discurso de comemoração aos 50 anos do Ginásio de Jequié). Jequié, [1985b]. Mimeografado.

PINHEIRO, R. M. Pronunciamentos que me emocionaram. O mestre e o aprendiz. In: RABELO, M. de A. Narrativa de uma existência. Jequié: UESB, 2005. p. 287- 289.

RABELO, M. de A. Narrativa de uma existência. Jequié: UESB, 2005.

RIO DE JANEIRO. Decreto-Lei no 4.642, de 2 de setembro de 1942. Dispõe sobre as bases de organização da instrução prémilitar. Diário Oficial da União. Rio de Janeiro, 04 set. 1942. Seção 1, p. 13521. Disponível em: http://www2.camara.leg.br/legin/ fed/declei/1940-1949/decreto-lei-4642-2-setembro-1942-414557publicacaooriginal-1-pe.html. Acesso em: 06 jan. 2019.

RIOS, D. R. Jequié, sintese histórica e informativa. 2. ed. Salvador: JM Gráfica e Editora Ltda., 2011.

RODRIGUES, J. R. G. Os debates acerca da educação secundária na Bahia: décadas de 1940 e 1950. In: MENEZES, J. M. F. de; PAIVA, M. M. de; AQUINO, M. S. (org.). História e memória da educação na Bahia: fortalecendo redes de pesquisa. Salvador: EDUNEB, 2012. p. 57-82.

SAMPAIO, J. F. Entrevista [21 nov. 2017]. Entrevistadora: Marly Gonçalves da Silva (arquivo particular). Entrevista gravada no dia 21 de novembro de 2017, em Jequié-BA, para a pesquisa de Mestrado do PPGECFP da UESB.

SANTANA, E. C. Anísio Teixeira e a Expansão do Ensino Secundário: ginásios e colégios na Bahia nas décadas de 40 a 60 do século XX. In: COLÓQUIO DO MUSEU PEDAGÓGICO, 8., 2009, Vitória da Conquista. Anais [...]. Vitória da Conquista: UESB, 2009. p. 335-356.

SANTOS, G. C. dos. Religião, sociedade e educação: a atuação do Padre. Demócrito Mendes de Barros em Serrinha (Ba): 1950-1992. 2006. 
269 f. Tese (Doutorado em Educação) - Faculdade de Educação da Universidade de São Paulo, São Paulo, 2006.

SANTOS, C. S. P. dos. História da formação docente no curso normal do Instituto de Educação Régis Pacheco (1959-1971): o ensino da matemática em foco. 2018. Dissertação (Mestrado em Educação Científica e Formação de Professores) - Departamento de Ciências Biológicas, Universidade Estadual do Sudoeste da Bahia, Jequié, 2018.

SILVA, M. J. da. De jovens piedosas a rainhas dos lares: formação de professoras no Ginásio Santa Bernadete em Amargosa-BA, 1953/1973. 2013. Dissertação (Mestrado em História Regional e Local) Departamento de Ciências Humanas, Universidade do Estado da Bahia, Santo Antonio de Jesus, 2013.

VALENTE, W. R. et al. A matemática na formação de professores e no ensino: processos e dinâmicas de produção de um saber profissional, 1890-1990. Projeto de Pesquisa. São Paulo: FAPESP, 2017.

Submetido em 07/04/2020. Aceito em 25/09/2020. 